\title{
A ESCRITA DA HISTÓRIA E DO LUTO NAS CATÁSTROFES COLETIVAS
}

Karla Patrícia Holanda Martins

Universidade Federal do Ceará

Fabiano Chagas Rabêlo

Universidade Federal do Delta do Parnaíba
Recebido em: 27/07/2020

$1^{\text {a }}$ revisão em: 30/10/2020

Aceito em: 08/11/2020

\section{RESUMO}

O presente artigo objetiva explorar, a partir das questões levantadas pela pandemia do Covid-19, a tensão e a pluralidade de sentidos que o conceito de desmentido assume no âmbito da psicanálise, considerando-se as acepções de Freud e Ferenczi. Busca-se uma articulação entre as contribuições desses dois autores para estabelecer daí uma descrição das consequências de uma política negacionista que perpetua e agrava as vulnerabilidades e o sofrimento da população mais desfavorecida, sobretudo em situações de catástrofes coletivas, como a atual. Criam-se daí obstáculos ao trabalho de simbolização e elaboração de lutos, limitando consideravelmente as possibilidades de construção de uma resposta política solidária, ampla, efetiva e duradoura. Problematiza-se então a relação entre a escrita da História e a dimensão coletiva do luto. Propõe-se, a partir de Freud e Ginzburg, a valorização da melancolia e da vergonha como estratégia de resistência discursiva a uma política negacionista alicerçada no desmentido.

Palavras-chave: psicanálise; história; luto. 


\section{THE WRITING OF HISTORY AND MOURNING IN COLLECTIVE DISASTERS}

\section{ABSTRACT}

This article explores, based on the issues raised by the Covid-19 pandemic, the tension and the plurality of meanings that the concept of denial assumes in the scope of psychoanalysis. An articulation between the contributions of Freud and Ferenczi is sought to establish a description of the consequences of a negationist policy that perpetuates and exacerbates the vulnerabilities and suffering of the most disadvantaged population, especially in situations of collective catastrophes, such as the current one. This creates obstacles to the work of symbolizing and elaborating mourning, considerably limiting the possibilities of building a solidary, broad, effective and lasting political response. Then, the relationship between the writing of history and the collective dimension of mourning is questioned. It is proposed, from Freud and Ginzburg, the valorization of melancholy and shame as a strategy of discursive resistance to a negationist policy based on denial.

Keywords: psychoanalysis; history; mourning. 


\section{LA ESCRITURA DE LA HISTORIA Y DEL LUTO EN DESASTRES COLECTIVOS}

\section{RESUMEN}

Este artículo explora, en base a los problemas planteados por la pandemia de Covid-19, la tensión y la pluralidad de significados que el concepto de negación asume en el ámbito del psicoanálisis. Se busca una articulación entre las contribuciones de Freud y Ferenczi sobre este tema para establecer una descripción de las consecuencias de una política negacionista que perpetúa y exacerba las vulnerabilidades y el sufrimiento de la población más desfavorecida, especialmente en situaciones de catástrofes colectivas, como la actual. A partir de esto, se crean obstáculos para el trabajo de simbolizar y elaborar el duelo, lo que limita considerablemente las posibilidades de construir una respuesta política solidaria, amplia, efectiva y duradera. Luego, se cuestiona la relación entre la escritura de la historia y la dimensión colectiva del duelo. Se propone entonces la valorización de la melancolía y la vergüenza como estrategia de resistencia discursiva a una política negacionista.

Palabras clave: psicoanálisis; historia; luto. 


\section{INTRODUÇÃO}

O presente artigo propõe uma reflexão sobre as questões do luto e da melancolia na cena contemporânea brasileira relacionada aos contextos da pandemia do Covid 19. A palavra contexto é empregada no plural para destacar que a pandemia não afeta de modo igual a todos. Há, portanto, várias pandemias, se consideramos as dimensões subjetivas, orgânicas e também as diferenças culturais, políticas e, principalmente, as desigualdades sociais e econômicas do estado federativo brasileiro, onde apenas $1 \%$ da população detém $30 \%$ da riqueza nacional. Logo, não estamos igualmente vulneráveis e as desigualdades, mesmo quando escamoteadas pelos atores políticos que deveriam estar comprometidos em combatê-las, tornam-se com a pandemia radicalmente visibilizadas e seus efeitos, potencializados.

O contexto geral da pandemia é marcado por uma estratégia discursiva sustentada pelos dirigentes políticos e por parte da elite e das mídias, que buscam por meio de uma série de afirmações e atos desqualificar o peso e a importância dessas gritantes desigualdades, valendo-se para tanto de uma operação que no plano social pode ser qualificada como análoga ao que Freud chamou de Verleugnung ao se referir ao mecanismo intrapsíquico de constituição do fetichismo (Freud, 1927/2014; Miranda, 2012).

Chamamos atenção para a complexidade da tradução desse termo, enfatizando a sugestão de Laplanche e Pontalis (1985, p. 564), que o descreve como a "recusa do que é devido", e ainda uma "recusa ilegítima" que incide "não apenas numa afirmação que se contesta, mas também num direito ou num bem que não se concede". Acrescentamos que essa recusa está associada ainda às formas de indiferença frente ao agravo e ao sofrimento experimentado pelo outro (Ferenczi, 1927-28/1992a; 1934/1992c), fertilizando um terreno a partir do qual brotam as sementes dos discursos e das práticas totalitárias dos regimes sociais de exceção que colocam a diferença como alvo para a destruição.

Dessa forma, os argumentos que são desenvolvidos nesse artigo exploram a tensão e a pluralidade de sentidos que a Verleugnung assume no âmbito da psicanálise. Identifica-se duas acepções principais, a freudiana e a ferencziana que são apresentadas e comentadas ao longo deste trabalho. Busca-se a articulação entre esses dois sentidos para estabelecer daí uma descrição mais precisa das nefastas consequências dessa política negacionista, que não só produz mortes em grande escala, mas também cria um complexo mecanismo que perpetua e agrava as vulnerabilidades e o sofrimento da população mais desfavorecida.

Enquanto a estratégia de defesa psíquica que opera especialmente entre os níveis da realidade e da linguagem, o desmentido será pensado aqui como um obstáculo ao trabalho de simbolização e elaboração dos lutos e perdas. Sugerimos pensá-lo como uma operação que poderia produzir, em contraponto, uma posição subjetiva que guarda os traços de uma melancolização, o que, a nosso ver, pode embasar 
uma estratégia de resistência política ao negacionismo, se explorada. Para respaldar esse argumento, resgata-se a contribuição freudiana presente em Luto e a melancolia (Freud, 1917/2011). Nesse texto, a melancolia é tomada como uma estratégia de denúncia das feridas narcísicas, o que pode subsidiar a escrita da História e o agenciamento de um trabalho coletivo de luto. Nesse sentido, o resgate das situações traumáticas sociais escamoteadas na historiografia oficial ganha relevância.

Sob essa perspectiva, traz-se à baila a ideia de vergonha como um cimento social edificante e civilizatório, tal como defendido por Ginzburg (2020), para em seguida comentar a distinção presente na língua alemã entre os termos Mahnmal e Denkmal, ambos traduzidos para o português como monumento. Perguntamos então sobre os eventos marcantes catastróficos da história recente, a brasileira e a cearense, que necessitam serem rememorados como parte importante da escrita da História e da elaboração singular do sofrimento.

\section{PANDEMIA, CATÁSTROFE E DESMENTIDO}

Em 1917, Freud (1917/2010) analisa as dificuldades no caminho da psicanálise a partir das três feridas que impactaram a unidade de pensamento ocidental moderno: o homem não é o centro do universo (Copérnico), o homem não é o senhor da sua própria casa (Freud) e o homem não está desconectado na natureza (Darwin). Se a essa lista acrescentamos a ferida narcísica produzida por Marx, que se caracteriza pela inclusão do homem numa dimensão histórica marcada pelo conflito e pela luta de classes, chegamos a uma quinta ferida narcísica, cuja marca principal é a urgência do reconhecimento do impacto ecológico, econômico e social causado pelo avanço do capitalismo e do uso instrumentalizado e eticamente desimplicado que é feito da ciência.

Desse modo, a operação de desmentido dos agravos da pandemia é tomada como uma forma de reação discursiva e política ao risco representado por esses cortes narcísicos.

Em sua generalidade, a pandemia é uma ferida que não escolhe órgão e faz entrar em colapso o corpo inteiro. Ela atinge igualmente os fundamentos do capital, desencadeando angústia, medo, desorientação, desconfiança e o sentimento de ameaça na nossa relação de cada um com os espaços públicos. Percebe-se um forte abalo das figuras do pacto social estabelecido. A catástrofe é tomada, portanto, como uma atualização e síntese das feridas narcísicas acima elencadas.

Com isso, a pandemia pode, do ponto de vista social, assumir o peso traumático de uma catástrofe, resgatada em seu sentido etimológico de kata -, "para baixo" + strophé, "virar", podendo também corresponder, como nos sugerem, SeligmannSilva (2000, p. 8), a ideia de "desastre", "desabamento". Trata-se, portanto, de uma experiência de súbita transformação ou virada, impondo àquele que a experimenta uma realocação de sua posição, que se reflete em termos subjetivos como a 
exigência de realização de um trabalho psíquico que dê suporte a esse movimento de acomodação.

Esse sentido atribuído à catástrofe, relativo ao que força uma transformação, também está presente no uso que Ferenczi (1924/1993, 1933/1992b) faz desse termo, onde o valor traumático atribuído a um determinado evento relaciona-se às condições encontradas pelo sujeito para responder e representar à súbita mudança de rumo ao qual ele é confrontado.

A pandemia atual é única, pois as condições de possibilidade para sua deflagração fazem desta um acontecimento histórico sem igual, mas não sem precedentes. Representa também a condensação de vários tempos. Dessa forma, toda pandemia pertence à História e, como tal, sofre a mediação da forma como os eventos catastróficos foram transmitidos e elaborados. Por outro lado, em cada pandemia o momento de sua irrupção e a forma de fratura que ela engendra são inéditos.

Quando cavamos as camadas da memória social de outros graves acometimentos na saúde pública brasileira encontramos restos de acontecimentos que foram esquecidos ou mesmo escondidos da História contada oficialmente. Essas memórias latentes trazem consigo signos que representam núcleos por nós recusados. Na medida em que tais signos são atualizados, velhas angústias irrompem e os desmentidos da nossa História retornam com a força da água represada de um dique aberto.

Vale salientar que o percurso de construção da metapsicologia psicanalítica é marcado por duas catástrofes coletivas, representadas por duas guerras mundiais, que foi entremeada por uma crise econômica de proporção global, fatos que impactaram e influenciaram a obra de Freud e de seus contemporâneos. Salientamos aqui o período da primeira guerra, quando ocorreu a última grande pandemia, a gripe espanhola, que ocasionou a morte da filha mais velha de Freud, Sophie, em 1920 (Gay, 1988).

\section{O LUTO NA PANDEMIA}

O período que abrange os anos após o início da primeira grande guerra, em 1915, pode ser avaliado, retrospectivamente, como extremamente fértil para o desenvolvimento da metapsicologia freudiana. Os conceitos gestados nesse momento histórico subsidiam as discussões aqui propostas. Nele Freud escreve, além do já citado Luto e Melancolia (Freud, 1917/2011), o texto Sobre a transitoriedade (Freud, 1916/1984). Nesse, o autor analisa o "penoso desalento" sentido pelo jovem poeta Rainner Maria Rilke frente à transitoriedade do belo e a consequente perda de seu valor. Em sua discordância, Freud (1916/1984, p. 345) afirma: "O valor da transitoriedade é o valor da escassez do tempo".

Trazendo essas palavras para os dias atuais, é necessário destacar que o elogio freudiano à transitoriedade jamais foi cínico ou sádico. Ele passa longe do "E daí? Vamos todos morrer", pois nele está incluído o reconhecimento de nossa história 
e a indagação ética sobre o que faremos e o que podemos fazer enquanto estamos vivos. É porque conhecemos a nossa a finitude e fazemos um luto da crença onipotente de que somos eternos, que a beleza se torna passível de fruição. A impossibilidade do luto frente à negação pelo outro da experiência de sofrimento torna-nos vulneráveis ao ressentimento e, não menos importante, à renúncia pulsional. Para Freud, trata-se de uma espécie de renúncia ao usufruto da vida, referindo-se literalmente a sua dimensão libidinal.

Neste estado de negação de nossa transitoriedade, renunciamos à fruição da beleza, da palavra e, sobretudo, da libido, moeda importante para o laço entre os homens e, como nos lembra Safatle (2006), moeda da política. Se o luto chega ao termo (há muito o que pensar sobre o bem-dizer do luto), em termos freudianos, estamos novamente liberados para inventar, valorizar e investir novas formas de vida. Do contrário, permanecemos vulneráveis ao medo e ao sofrimento patológico, à melancolia. A saúde mental está irremediavelmente ligada, neste pequeno ensaio de Freud (1916/1984), à manutenção da nossa capacidade de nos encantarmos com as coisas miúdas, aquelas que nos fazem, quando o cansaço nos permite, voltar a sentir que a vida vale ser vivida.

Propomos então tratar, a partir do pensamento psicanalítico de Freud (1917/2011) e Ferenczi (1933/1992b), a desautorização social do luto como um fator de vulnerabilização ao trauma e à melancolização.

Sobre o luto podemos dizer:

1. O luto é uma modalidade de trabalho psíquico que intercruza a dimensão da singularidade a aspectos culturais relacionados às práticas de vida e morte dos seres humanos. Portanto, o luto é um estado, mas é sobremaneira um fazendo juntos; o luto possui uma dimensão pública e política que lhe é intrínseca;

2. O luto é uma experiência tecida numa dimensão que enreda a transmissão cultural;

3. O luto não diz respeito apenas a uma perda ou ao desaparecimento de um objeto, mas também à perda de um ideal;

4. O luto é um processo instaurador das novas condições de pensamento e de simbolização; portanto, ele se dá no contraponto à violência do nãoreconhecimento do sofrimento e da indiferença a esse sofrimento;

5. O pathos do luto pressupõe um sofrimento no sentido de sermos afetados por uma experiência que se impõe [de fora] como realidade, mas o pathos do luto não deve ser considerado como doença;

6. O luto está ainda colocado em articulação com as nossas condições para realizálo. Condições essas singulares, relacionadas à história particular de cada um de nós, mas ainda à nossa História, com $\mathrm{H}$ maiúsculo, enquanto narrativa coletiva, 
portanto, relacionada às dimensões do reconhecimento social dos nossos direitos humanos, do respeito às nossas condições de vida e da nossa relação de confiança com o mundo;

7. Dito isso podemos perguntar na outra ponta: e quando o luto se faz traumático, no sentido de disparar uma forma de sofrimento que nos imobiliza, colapsando a nossa dimensão psíquica, provocando uma espécie de desabamento, acrescentando ao seu domínio uma experiência subjetiva e coletiva de perda que colapsa a nossa crença no futuro, a confiança em si e nos outros humanos, tornando-nos invisível na cena mesma do desastre?

Ferenczi (1933/1992b) sublinhou o caráter intersubjetivo e social da cena traumática, destacando nela o valor do desmentido e da desautorização subjetiva. O caráter traumático de uma experiência é estabelecida a partir da ação do desmentido, que consiste no descredenciamento da palavra de quem testemunha a ferida ou o agravo sofrido, o que acarreta, por extensão, a desvalorização de sua própria vida. Desmentir significa, portanto, desacreditar ou desautorizar a dor que acompanha a experiência subjetiva daquele(s) que relata $(\mathrm{m})$ a experiência traumática. Os destinos subjetivos dessas experiências dependem assim da presença de um fiador da representação. Por isso, no campo desses estudos, temse proposto um caráter testemunhal na presença do trauma.

Do ponto de vista de uma extensão do pensamento ferencziano, pode-se afirmar que a possibilidade de uma escrita dessa História encontra-se dependente do reconhecimento, como oficial, do que foi testemunhado. Em outro contexto, sugerimos pensar a ausência do reconhecimento da ocorrência de campos de concentração na História do Ceará como uma ilustração dos desmentidos históricos (Martins \& Kupermann, 2017).

Destino semelhante ameaça os testemunhos da ditadura militar brasileira quando torturadores são exaltados e os relatos de quem viveu o horror são desacreditados. A negação de um acontecimento social traumático tem um caráter disruptivo, de esgarçamento do laço, do nós e dos nós. Quando abafadas, entubadas parafraseando um termo atualmente em voga que evoca ao mesmo tempo o risco iminente de morte e o silenciamento da palavra - essas experiências tendem a reaparições. Dito de outro modo, quando mandadas de volta ao esquecimento, sem um trabalho de elaboração dos sofrimentos e das perdas que thes são associadas, sua tendência é forçar seu reconhecimento por uma via que é da reatualização do trauma. Transformadas em experiências-tabu, adquirem o estatuto de uma ferida incurável, intratável e inelutável. Do ponto de vista ferencziano, do lado daquele que sofre, à violência do descrédito sobrevém a culpa ou uma espécie de coma psíquico, situação marcada pela apatia, a vergonha ou, ainda, a possibilidade de uma identificação com o agressor.

É através desse regime de negação, desmentido e descrédito que a pandemia, no contexto do Estado brasileiro atual, vem se transformando em uma ferida que atualiza a série das nossas mais graves catástrofes históricas. Há um núcleo 
necropolítico do Estado brasileiro que conseguiu passar incólume. Em um só golpe (ou dois), são reunidas as feridas produzidas no tecido social e cultural brasileiro ao longo de nossa História pelo nosso racismo, pelo desmentido da fome, das nossas desigualdades sociais e da tortura e da morte vividas durante o último regime ditatorial.

A pandemia deixará um rastro novo na nossa memória, mas, ao mesmo tempo, ela representa a metáfora atual do conjunto dos lutos que não foram feitos ao longo de nossa História. A não realização do luto nos vulnerabiliza em relação à aparição de regimes totalitários, renunciamos à nossa liberdade, aqui entendida como reconhecimento da nossa sobredeterminação.

\section{O DESMENTIDO HISTÓRICO DA FOME E OS CAMPOS DE CONCENTRAÇÃO CEARENSES}

A exemplo do que estamos sugerindo pensar como desmentido histórico e os efeitos do seu retorno, analisaremos a seguir os elementos da crise sanitária dos anos de 1877-78 vivida no Estado do Ceará, por ocasião da grave seca que atingiu o sertão central, forçando a migração de milhares de sertanejos para capital que, então com 30.000 habitantes, chegou a atingir uma população de cerca de 100.000 pessoas.

Naquela ocasião, a fome e as pestes, em especial a varíola, chegaram a matar na capital, em um só dia, nada menos que 1004 pessoas. Dez de dezembro de 1878 ficou conhecido nos jornais da época como o Dia dos Mil Mortos. Os doentes, quando sobreviviam, eram removidos pela força policial para os abarracamentos afastados do centro da cidade, mais tarde denominados os primeiros campos de concentração cearenses (Rios, 2014).

O escritor e sociólogo Lira Neto (Cavalcante Neto, 1999) faz um pungente relato do sofrimento e da indiferença do poder público para com a morte naqueles anos de seca, fome e pandemia na sua obra biográfica do farmacêutico e escritor Rodolfo Teófilo e de reconto desses dias, sublinhando a vergonha sentida por este com o transporte público dos moribundos: pessoas doentes eram conduzidas pelas ruas da cidade em redes, por sertanejos igualmente famintos que para suportarem o trabalho eram pagos à base pinga, farinha e carne seca; trôpegos caminhavam por mais de três quilômetros carregando os corpos de velhos, crianças, homens e mulheres seminus, urrando de dor com suas feridas causadas pela varíola. Corpos mortos se amontoavam pela cidade, como também no trajeto estadual da estrada de ferro que ligava o sertão à capital. A omissão dos governantes ofendia a dignidade não apenas da vida, mas, também, do morrer. Alguns se contrapunham ao descaso com milhares de mortes e denunciavam o genocídio provocado pela indiferença dos políticos através dos jornais locais e na imprensa nacional. É desta época o conjunto de fotografias que deu rosto à fome e à seca das províncias do Norte, todas estas feitas, no ano de 1878, por um dos precursores do fotojornalismo brasileiro, Joaquim Antônio Corrêa (Correa, 1879; Leite, 2019). 
O destino da verdade histórica sobre os campos de concentração do Estado pode ser considerado um símbolo do elo perdido das experiências da seca, da fome, da doença e do horror à morte que foram apagados da nossa história. A luta de Rodolfo Teófilo e sua esposa Raimunda Cabral contra a varíola, no início do século $\mathrm{XX}$, deveria fazer parte da história transmitida às gerações que os sucederam. $\mathrm{O}$ casal fabricou, por iniciativa própria, a vacina para varíola e, até o ano de 1901, 3585 pessoas já haviam sido imunizadas na capital. Rodolfo Teófilo saía em seu cavalo pelas areiais de Fortaleza, como eram conhecidos os bairros mais afastados do centro e próximo às dunas, indo de casa em casa. Ao chegar nas residências negociava com o medo das famílias a aplicação da vacina, contando estórias sobre cavaleiro da morte ou, às vezes, pagando alguns vinténs às crianças e, no extremo, ameaçando as famílias de prisão. O farmacêutico chegou a formar uma liga de vacinação no interior, mandando pessoalmente cartas a 79 municípios, que se associaram a ele para imunizar parte de suas populações. A iniciativa estóica do farmacêutico custou sua demissão da cátedra por ele ocupada no Liceu Cearense, entre outras perseguições políticas do governador da Província, Nogueira Acioly, que, de forma muito atual, espalhava nos jornais notícias falsas sobre crianças que teriam morrido após serem vacinadas.

A obra literária de Rodolfo Teófilo (1890/1979) representa um testemunho desses dias, memórias que presentificam a ausência do que, já naquele momento e ainda hoje, jamais pode ser pensado, dito ou reconhecido enquanto uma experiência subjetiva e coletiva. Seu livro $A$ fome é reconhecido pela crítica literária como uma obra que teria colocado em cena o corpo faminto, dando rosto aos incontáveis retirantes esfomeados, nomeando o desprezo e a invisibilidade por eles adquirida aos olhos do poder que deveria ser público e de proteção. Ali a fome é uma figura da radicalidade do nosso desamparo e do nosso abandono. A história de Manoel Freitas, personagem principal dessa obra, transforma-se na nossa História. O trauma é então circunscrito, nomeado e elaborado por meio de sua narrativa social.

\section{ENFRENTAMENTO DO DESMENTIDO I: A MELANCOLIA}

No argumento central do texto de Freud (1917/2011), a melancolia é trazida em contraponto ao luto. Ela é considerada um destino patológico do luto não realizado: desalento penoso frente à perda de algo que não pode ser elaborada e não foi suficientemente pranteada. Trata-se de um processo que leva o sujeito a uma identificação narcísica com o que foi perdido. A sombra do objeto engolfa o eu e, assimilado ao que foi perdido, subsume à dor. Todavia, num ponto de inflexão à sua renúncia do mundo, não desiste de denunciá-lo. A linguagem é sua arma.

Teresa Pinheiro (2016) se propôs a pensar a presença na melancolia de um texto denominado por texto imagético que se caracteriza pela formalização de uma cena através de um arranjo estilístico de fala marcado pelo excesso descritivo e o apreço pela exatidão das palavras e regras de sintaxe, anulando, em nome desse projeto de formalização e busca da perfeição, a polissemia e a ambiguidade das palavras. O texto imagético cumpre ainda a função de descrever o que foi testemunhado 
em contraponto a uma perspectiva que se propõe interpretativa de sua experiência. Nestas circunstâncias, a função polissêmica da palavra se enfraquece frente à ambição de uma verdade absoluta, marcada por um certo apreço à mostração, que incita aquele que escuta a ocupar o lugar de 'mero' espectador da cena, acossando-o numa experiência subjetiva de espanto e impotência. Todavia, não se trata aqui do caráter teatral da cena histeria, a referência aqui não é o teatro, muito menos a interpretação, mas uma tentativa de circunscrição, de descrição do objeto.

Freud (1917/2011) já havia se surpreendido com a ideia de auto-desnudamento do melancólico: como alguém pode ser tão lúcido sobre sua pequenez, tão fiel à sua imagem? A vergonha parecia ausente desse julgamento. Pinheiro (2016) chama a atenção para o significante destacado por Carone (2011) em sua tradução do termo alemão Klage, que significa queixa. A chave da leitura freudiana estaria nesse termo - "Ihre Klagen sind Anklagen": "queixar-se é dar queixa" (Carone, 2011, p. 92) - portanto, é denunciar a impostura, a pequenez moral desse outro idealizado. O melancólico aspira o absoluto, mas evoca-o para destituí-lo. Recobrir o objeto perdido com as vestes do príncipe, aparentemente levando-o à condição de perfeição, corresponde à absolutização de uma verdade. Todavia, a manta cobre um rei nu e déspota, figura que nos remete aos desígnios do supereu.

É necessário destacar que a melancolia é uma figura de fronteira. Aqui está a sua riqueza e fertilidade. Freud foi igualmente um homem marcado pelas referências estéticas do renascimento, foi barroco e benjaminiano a seu modo, nos deixando aqui outras possibilidades de leitura, dando-nos uma pista do porquê da não assimilação da melancolia à depressão. O melancólico é um homem da ação. Sua excepcionalidade, seu transbordamento encontram seu ponto de basta na ação criativa: essa é a tese do Problema XXX de Aristóteles (1997). Todavia, no torpor, no seu coma/furor de quem renunciou à sua natureza política, Lacan (195960/1997) irá pensar essa desistência como uma espécie de covardia moral. Há uma positividade na melancolia: no seu avesso, é uma figura da política afirmativa, propositiva, aquela que não se engana. Todavia, como todo avesso tem um direito, e no caso aqui, uma direita, ela pode ser assimilada pelo ato da renúncia e da desistência, não sem antes levar consigo o Outro. Para além da decepção, há uma linha tênue, um ponto de virada, entre a renúncia e a criação. Há aqueles que permanecem decepcionados, ressentidos com o não cumprimento da promessa.

Susana Lages (2007) faz uma importante aproximação entre o trabalho do melancólico e o trabalho do tradutor: ambos precisam se emancipar, recriar a língua originária do texto; ultrapassar o texto original para dizer algo em nome próprio, recriar o texto original é parte do trabalho psíquico a ser realizado na melancolia. Trazendo o Outro em língua própria, hospedar o mais estranho, ou, como propôs Neusa Santos (Santos Souza, 1996) em referência a Nietzsche, renomeando o nosso mal como o melhor de nós mesmos. 
O que há na cena atual que nos reporta à melancolia? O que aconteceu na história brasileira quando se fez necessário fundarmos o nosso próprio nome? O que significa, por exemplo, chamar à cena os emblemas pátrios para dar sustentação a um projeto de pátria e nação?

\section{ENFRENTAMENTO DO DESMENTIDO II: A VERGONHA}

A vergonha parece ser um elemento decisivo na escolha por uma via de elaboração ou negação de um evento catastrófico. Ginzburg (2020) defende que esse sentimento não deve ser simplesmente qualificado como um afeto relacionado ao ressentimento ou a autodepreciação. Ele abarca igualmente uma dimensão construtiva e edificante, que o qualifica como um importante catalisador dos laços sociais em direção a uma mobilização política.

Para Ginzburg (2020), a vergonha possui uma importante função política. Ela vem mostrar que a fronteira do eu não se limita ao individual. Ela inclui o Outro, os ideais, signos e imagens compartilhados, que são fundamentais para a construção de identidade de si, como pessoa, grupo, categoria ou nação.

Nesse sentido, a política do negacionismo vem tolher a incidência positiva desse sentimento, embargando uma disposição para agir de forma coletiva que ele fomenta, algo precioso, sobretudo numa situação de urgência como a da atual pandemia, que exige uma prontidão para intervir não só de forma pontual, no momento que se segue a catástrofe, mas também de maneira coordenada e planifica a médio e longo prazo, articulando e potencializando os efeitos das políticas e dos recursos públicos.

Aqui o uso de forma lúcida e elaborada da memória das experiências históricas acumuladas se mostra de fundamental importância, sobretudo dos fracassos e das máculas coletivas. A esse respeito, considera-se valiosa a sutileza da distinção presente na língua alemã entre Denkmal e Mahnmal, que se perde quase que completamente na tradução para o português como monumento. Mesmo reconhecendo que a função de todo monumento é a rememoração de um fato marcante, é possível qualificar diferentes modos e estratégias de rememoração. Denken evoca simplesmente o ato de pensar, de rememorar. Pode-se dizer que Denkmal constitui uma forma geral do conceito de monumento que engloba o Mahnmal como um subtipo. Este traz a ideia de uma lembrança envergonhada de caráter admoestatório. Mahnen significa admoestar, é a lembrança pesarosa de um fato doloroso que pode infelizmente se repetir, como os campos de concentração alemães na segunda guerra.

Essa referência nos faz pensar sobre a qualidade de nossos monumentos, que geralmente evoca heróis da nação, cujos feitos devemos nos orgulhar. Geralmente homens, brancos, de família abastadas. E as tantas catástrofes, massacres e pandemias que fazem parte da nossa construção de identidade como nação? Mesmo os monumentos dedicados a esses acontecimentos costumam cooptar a 
imagem de um herói susposto redentor, negando com o isso o sentimento de vergonha atrelado a essas lembranças.

Nesse ponto da discussão, é pertinente regatar alguns episódios históricos do Brasil, que participaram da formação de sua identidade como nação.

No ocaso de seu reinado, no final da década de 1880, o imperador D. Pedro II foi forçado a trazer para o centro da cena brasileira a seca das províncias do norte onde se incluíam os estados do Nordeste atual - a partir das pressões protagonizadas pela imprensa carioca. A unidade nacional por ele pretendida se fazia em torno da incorporação dos pobres e famintos dessas províncias. Nessa observação, não há um apreço pelo regime monárquico, as soluções do presente não se encontram na reprodução técnica do passado. Trago essa operação posto que ela expressa a ideia de um passo à frente que se faz dependente do trabalho de inclusão e incorporação do que ficara para atrás como resto inassimilável. A frase proferida na ocasião se imortalizou, ele diz: venderia até a última joia da coroa para acabar com a seca e alimentar os famintos das províncias do norte. Como incluir no processo civilizatório brasileiro aqueles que foram excluídos sistematicamente pela nossa história? O destino de $d$. Pedro todos já conhecem...

É nesse contexto que nasce a república federativa brasileira sob as hostes parnasianas da bandeira nacional - ordem e progresso. Bilac foi o seu poeta. O parnasianismo, seu estilo. Sob o comando desta república militarizada, Canudos foi destruída (Pinheiro \& Martins, 2001).

Retomamos aqui uma ideia trabalhada nos últimos anos (também já proposta por outros autores) de que o sertão, para além da delimitação de um espaço geográfico, serviu, sobretudo, para a formação do pensamento brasileiro moderno, como uma espécie de espaço ficcional, mito fundador para a construção de um ideal de nação (Martins, 2014). Marilena Chauí (2000, p.9), em Brasil: mito fundador e sociedade autoritária, define mito fundador como "aquele que não cessa de encontrar novos meios para exprimir-se, novas linguagens, novos valores e ideias, de tal modo que, quanto mais parece ser outra coisa mais é a repetição de si mesmo". Dito de outro modo, o sertão emprestou sua paisagem, seu rosto, para fundar um novo espelho a partir do qual o Brasil se inventou, se olhou, (e agora podemos dizer também, mais uma vez) se escondeu. Ou seja, o sertão de Conselheiro diz de um Brasil de ontem e de hoje, visto que a história é sempre construída em várias camadas; algumas parecem fossilizadas, até que são novamente despertadas!

Segue-se aqui uma legião de órfãos - Euclides da Cunha, Lima Barreto, Graciliano Ramos nossos aedos, nossos profetas. Nossos tristes visionários, como nos propõe Lilian Schwarcz (2017). Mas vejam, e Lilian nos chama atenção para o triste e visionário Policarpo Quaresma, cujo sobrenome significa fruto da espera da ressurreição, do renascimento, o que não pode e não deveria se confundir com a espera da grande verdade, seja no campo da política seja no da religião. 
Trazemos elementos para lembrar que talvez a fúria antropofágica (igualmente necessária) tenha canibalizado - ou carnavalizado demais e muito precocemente uma tristeza necessária. Graciliano Ramos (1981, p.60), ácido e irônico, denunciará a nação macaqueada, a pressa do carnaval. "A pátria é um orangotango; nós somos um sagui. Diversidade em tamanho, inclinações idênticas. Imitações, adaptações, reproduções (...)"

Mais uma vez somos lembrados que fundar, criar uma língua, dar dignidade ao nosso nome, significa uma disposição para vender até as últimas joias da coroa. A bolsa ou a vida. Paulo Prado (1997, p.129) localiza o nosso colapso social e moral na cobiça: "Ouro. Ouro. Ouro".

Essa é igualmente uma questão clínica. Quando não suportamos em algum momento também empobrecer, perder as nossas joias, já que vão os anéis e ficam os dedos, negamos a tristeza e somos paralisados pela angústia e, paradoxalmente, pela renúncia. Precisamos suportar à tristeza do nosso tempo, não negarmos nosso desconhecimento, desnudar também nossa pequenez e nos identificamos com o trabalho do pensamento e da linguagem polissêmica, sem pressa para quando o carnaval chegar. Precisamos desses frutos, dos policarpos e da Quaresma! Para dizer como Leminski (2016, p. 284): "Um homem com uma dor é muito mais elegante. Caminha assim de lado como se chegando atrasado, andasse mais adiante"

\section{CONCLUSÃO}

Este texto nasceu da reflexão sobre as razões da indiferença e inoperância diante de uma situação catastrófica que, se não poderia ser evitada, poderia ser drasticamente reduzida, bastando para tanto uma mobilização coordenada em tempo hábil entre o estado e a sociedade civil. Isso porque, no início da pandemia em solo nacional, já se contava com informações preciosas sobre o seu modo de disseminação e as estratégias mais eficazes de contenção dos agravos. Ignorando inúmeros alertas e informações disponibilizados pela comunidade científica e pela OMS - Organização Mundial de Saúde -, o governo federal, alguns atores políticos e setores da impressa optaram por investir todas as fichas em uma estratégia temerária e controversa de resposta à catástrofe, o que contribui para aumentar exponencialmente os números de mortos. Assim, no auge da infecção, dois ministros da saúde foram demitidos por discordar da opinião do presidente e dos seus apoiadores mais próximos. As mortes de milhares de pessoas foram tratadas com indiferença e descaso a partir da premissa cínica e falsa de que o prolongamento da quarentena acarretaria na morte de empresas, CNPJs. Divulgouse que se enterravam caixões vazios, que os hospitais de campanha e as UTIs não estavam lotados como era noticiado, que tudo isso era encenação, fruto de uma campanha orquestrada contra o governo.

Essa situação, por sua vez, nos leva a questionar a letargia da sociedade civil. Por que não houve uma resposta ampla e coordenada de resistência a essa conjuntura? 
Claro, houve respostas incisivas por parte de alguns setores, mas essas não tiveram a repercussão necessária que a situação exigia.

Constatou-se justamente o contrário. O sentimento de patriotismo foi evocado para justificar o descaso com a vida de milhares de brasileiros. Urge então formular a pergunta: por que esse patriotismo não foi utilizado em defesa de seu bem mais precioso: a vida de sua população? Por que o patriotismo não se converteu em uma atitude solidária, que se impusesse frente as diferenças políticas, partidárias e ideológicas?

Defendeu-se que para gestar uma resposta razoável para essa questão é necessário questionar como no passado outras situações de catástrofes coletivas foram enfrentadas. A partir daí, desenvolveu-se o seguinte argumento: esquecemos as nossas catástrofes porque delas não fazemos lutos, não enterramos os nossos mortos ou, quando o fazemos, preservamos o anonimato destes. O que significa também dizer: recusamos uma escrita histórica de nossas catástrofes.

Em tempo: até o final do mês de julho de 2020, mais de 90.000 famílias no Brasil já haviam enterrado os seus mortos, sem cerimonial, sem despedida, solitariamente. Foram todos entubados (alguns, nem isso). O trabalho da oralidade associado aos processos de introjeção e ao luto foram sustados. Não sabemos ainda o efeito dessa experiência de entubação, costurada com a História, a história do um, do cada um.

Gostaríamos de encerrar este trabalho com o argumento de que a psicanálise precisa, hoje, excepcionalmente, como nos propõe Koltai (2016, p.25) "escutar a História que emoldura as histórias" e, ainda, interpelar os efeitos subjetivos das históricas violências genocidas. Precisamos do luto e, arriscaremos, também da melancolia, tomada aqui enquanto afirmação de uma posição subjetiva que não teme a denúncia. Apostamos na possibilidade que, no futuro, como sugere Ginzburg, a vergonha possa matizar o destempero de um patriotismo mortífero.

Por fim, é importante assinalar que as ideias que foram expostas são fruto da convergência de várias linhas de pesquisa que são atualmente desenvolvidas no contexto da pós-graduação em psicologia da UFC. A articulação entre elas surgiu da urgência e da necessidade de um posicionamento clínico-político que a pandemia impôs. Gostaríamos de citar os temas dessas pesquisas, que possuem em comum o interesse e o compromisso ético em relação às diferentes formas de vulnerabilidade psíquica e a referência às contribuições de Freud e Ferenczi. São eles: os impactos subjetivos da fome - sobretudo na relação materno-infantil -, o racismo, a clínica do testemunho, as manifestações subjetivas da vergonha, a melancolia e a relação entre arte, estética, clínica e técnica. 


\section{REFERÊNCIAS}

Aristóteles. (1997). Problema XXX. In C. P. Almeida; \& J. M. Moura (Orgs.). A dor de existir e suas formas clínicas: tristeza, depressão e melancolia (p.23-35). Rio de Janeiro: Kalimeros.

Carone, M. (2011). Discussão de algumas divergências. In S. Freud, Luto e Melancolia (pp. 91-97). São Paulo: Cosac Naify.

Chauí, M. (2000). Brasil: mito fundador e sociedade autoritária. São Paulo: Editora Fundação Perseu Abramo.

Correa, J. A. (1878). Fotografia. Revista O Besouro. Rio de Janeiro. Disponível em http://brasilianafotografica.bn.br/brasiliana/browse?value=Secas+-

+Cear\%C3\%A1\&type=subject. Acesso em 10 janeiro de 2017.

Ferenczi, S. (1993). Talassa. Ensaio sobre a teoria da genitalidade. In S. Ferenczi, Obras completas: Psicanálise (Vol. III, pp.255-325). São Paulo: Martins Fontes. (Trabalho original publicado em 1924).

Ferenczi, S. (1992a). Elasticidade da técnica. In S. Ferenczi, Obras completas: Psicanálise (Vol. IV, pp. 25-36). São Paulo: Martins Fontes. (Trabalho original publicado em 1927-28).

Ferenczi, S. (1992b). Confusão de línguas entre os adultos e a criança. In S. Ferenczi, Obras completas: Psicanálise (Vol. IV, pp.97-106). São Paulo: Martins Fontes. (Trabalho original publicado em 1933).

Ferenczi, S. (1992c). Reflexões sobre o trauma. In S. Ferenczi, Obras completas: Psicanálise (Vol. III, pp.125-136). São Paulo: Martins Fontes. (Trabalho original publicado em1934).

Freud, S. (1984). A transitoriedade. In: S. Freud, Obras completas (Vol. 14, pp. 257-262). Rio de Janeiro: Imago. (Trabalho original publicado em 1916).

Freud, S. (2010). Uma dificuldade da psicanálise. In: S. Freud, Obras completas (Vol. 14, pp. 240-250). São Paulo: Companhia das Letras (Trabalho original publicado em 1917).

Freud, S. (2011). Luto e Melancolia. In: S. Freud, Luto e Melancolia (Tradução Marilena Carone). São Paulo: Cosac Naify. (Trabalho original publicado em 1917).

Freud, S. (2014). O Fetichismo. In: S. Freud, Obras completas (Vol. 17, pp. 302-310). São Paulo: Companhia das Letras. (Trabalho original publicado em 1927).

Gay, P. (1988). Freud: uma vida para nosso tempo. São Paulo: Companhia das Letras.

Ginzburg, C. (2020). O Vinculo da Vergonha. Serrote, edição esp(1). doi: 10.1017/CBO9781107415324.004.

Koltai, C. (2016). Entre psicanálise e história: o testemunho. Psicologia USP, 27(1). 24-30. doi: 10.1590/0103-6564D20150009

Lacan, J. (1997). Seminário, livro 7: a ética da psicanálise (1959-60). Rio de Janeiro: Jorge Zahar Ed.

Lages, S. K. (2007). Walter Benjamin: tradução e melancolia. São Paulo: EDUSP.

Laplanche, J., \& Pontalis, J.-B. (1985). Vocabulário de Psicanálise. São Paulo: Martins Fontes.

Leminski, P. (2016). Toda poesia. São Paulo: Companhia das Letras.

Leite, A. B. (2019). História da fotografia no Ceará no século XIX. Fortaleza: Ed. do autor.

Martins, K. P. H. (2014). Sertão e melancolia: espaços e fronteiras. Curitiba: Ed. Appris.

Martins, K. P. H., \& Kupermann, D. (2017). Fome: o umbral da vergonha. Trivium, 9(2), 199-209 doi:10.18379/2176-4891.2017v2p.199.

Miranda, H. F. (2012). Confusão de línguas: eficiência e deficiências da tradução. In J. Verztman (Org.) Sofrimentos Narcísicos (pp. 39-48). Rio de Janeiro: Cia de Freud. doi: 10.13140/RG.2.1.3712.4965.

Neto, L. (1999). O poder e a peste: a vida de Rodolfo Teófilo. Fortaleza: Edições Demócrito Rocha.

Prado, P. (1997). Retrato do Brasil. São Paulo: Companhia das Letras.

Pinheiro, M. T. (2016). Ferenczi. São Paulo: Casa do Psicólogo.

Pinheiro, M. T. S., \& Martins, K. P. H. (2001). O Texto imagético: parnasianismo e experiência analítica. In A. C. Lo Bianco (Org.), Formações teóricas da clínica (pp. 57-72). Rio de Janeiro: Contra Capa.

Ramos, G. (1981). Linhas Tortas. Rio de Janeiro/São Paulo: Record.

Rios, K. (2014). Isolamento e poder: Fortaleza e os campos de concentração na seca de 1932. Fortaleza: Imprensa Universitária.

Safatle. V. (2006). A paixão do negativo: Lacan e a dialética. São Paulo: Ed. UNESP,.

Santos Souza, N. (1996). Ética e clínica psicanalítica. In M. L. França (Org.), Ética, Psicanálise e sua Transmissão ( pp. 172-178). Petrópolis: Ed. Vozes.

Schwarcz, L. (2017). Lima Barreto: triste visionário. Companhia das Letras. 
Seligmann-Silva, M. (2000). A história como trauma. In M. Seligmann-Silva, \& N. Nestrovski (Orgs.) Catástrofe e representação (pp. 73-98.). São Paulo: Escuta.

Teófilo, R. (1979). A fome-violação. Rio de Janeiro: Ed. José Olympio. (Trabalho original publicado em 1890).

\section{CONFLITOS DE INTERESSES}

Não há conflitos de interesses.

\section{FINANCIAMENTO}

Conselho Nacional de Desenvolvimento Científico e Tecnológico (CNPq).

\section{SOBRE OS AUTORES}

Karla Patrícia Holanda Martins: psicanalista, professora nos cursos de graduação e pós-graduação em psicologia da UFC - Universidade Federal do Ceará, doutora em teoria Psicanalítica pela UFRJ, bolsista $P Q$ do $C N P Q$.

E-mail: kphm@uol.com.br

(iD) http://orcid.org/0000-0003-3242-6287

Fabiano Chagas Rabêlo: professor da UFDPar - Universidade Federal do Delta do Parnaíba, doutorando em Psicologia pela UFC - Universidade Federal do Ceará, psicanalista, participante da Letra Freudiana: Escola de Psicanálise.

E-mail: fabrabelo@gmail.com

(iD) http://orcid.org/0000-0001-5026-8396 